\title{
Ockham's Razor Makes Me Smile: Managing New Literacy Practices in Off Shore University Course Work in the Digital Age
}

\author{
Barb Garrick \\ Correspondence: Barb Garrick, School of Education and Professional Studies, Griffith University, Southport, \\ Australia. Tel: 61-7-5552-9790. E-mail: b.garrick@griffith.edu.au
}

Received: September 26, 2012 Accepted: October 30, 2012 Online Published: November 28, 2012

doi:10.5539/hes.v2n4p75

URL: http://dx.doi.org/10.5539/hes.v2n4p75

\begin{abstract}
Managing international cohorts of students who undertake workplace learning in countries other than the country of their host university can be a very complex and difficult process. University academics are accustomed to personal, face to face contact with their students. When students then move offshore, but remain the responsibility of the academics, there is often difficulty working in a virtual world of communication. This sorely tests the participants' concept of teaching and good pedagogy and can lead to the academic feeling a loss of intimacy or with-it-ness with their students. This paper investigates the use of a very simple social media tool to stay in regular and personal contact with students during their off-shore work placements. The paper will show that contact with students within a virtual environment up until recently is usually undertaken using older literacy practices such as emails. These simply become an electronic form of a handout or letter. Although crafted to avoid ambiguity, the emails nevertheless seem not to work in a virtual environment as they would do in a face to face environment. Drawing upon the literature, the point is made in this paper that contact with students in virtual environments can be made using social media tools that involve newer literacy practices.
\end{abstract}

Keywords: workplace learning, withitness, higher education, social media, blended learning, off-shore learning, new literacy practices

\section{Introducation}

\subsection{The Current Higher Education Terrain and the Use of Blended Learning}

The research reported in this paper is a very small section of a qualitative and longitudinal study into the internationalization of teaching degrees in relation to the Canadian higher education market. That study is entitled: Localising global babble: the individual narratives of students and teachers as they make sense of and benefit from an internationalised teaching degree. This is the first paper from that study. The participants in this broader study are students who travel in order to gain a university degree. One of the interventions undertaken within this broader study was to improve the support given to students when they return to their home countries to complete their degree. Following a year and a half of on-campus study, students in the pre-service teaching degrees at the university discussed here then undertake an internship in schools either locally or overseas in their home country. During the on-campus component of the programs I was their program convenor and was in constant and close contact with students. The nature of this contact changed of course once students went off-campus. One of my tasks as internship convenor was to ensure the smooth running of the internship program both locally and internationally and this paper describes one of the tasks undertaken. On-campus interventions involved the introduction of face to face, regular meetings and careful instructions in relation to the conduct of the internship. In 2010, the off-campus intervention included a visit to interns who had returned home to Canada for their internship.

What struck me immediately and "what I saw" (Rajchman, 1985, p.46) during this visit was the change in students I had known in Australia. My sense, and this was a personal reaction, was that students were more stressed and less likely to accept any hiccups with the program. I sensed that they had now counted our university out of their immediate environment and some students actively disengaged from that environment. Indeed, although I had travelled thousands of miles over countless hours and at cost to visit these students, several students were quite vocal in their disappointment at the timing and location of our on-site meetings. Something to me was "slightly cracked" (p.46) in our communication processes. The immediacy I had cultivated with these students while on campus in Australia was broken and not necessarily assuaged by the close proximity 
of a visit to these students in their home country.

My sense of distance from students was made more so through the electronic communication I was required to send concerning the internship process. The university where I was employed had only recently embraced blended learning and this was in a rudimentary implementation phase. I was provided with a set of emails and instructed as to the scheduled timing and distribution of these emails from the program convenor. The use of these emails had not previously been researched for efficacy and these were assumed to have worked. These emails (following) were crafted to provide careful and considered summaries of the information that students were also provided with in their internship handbooks.

Because I did not have authorial ownership of these emails, I felt a jarring between myself and the "institution with which I dealt" (Rajchman, 1985, p.46). There was a sense of a valorised and institutional discourse used in the emails that was intelligible to the owners of that discourse, but not necessarily to the recipients of that discourse, nor to me.

Of greatest concern to me though was the impact of these processes on "my relations with others" (Rajchman, 1985, p.46) and my established means of gaining presence with students. Not only did I feel embarrassment when students were less than understanding, but I also missed the teacher "with-it-ness" that I had cultivated with my students and began to doubt my teacher efficacy as a consequence. With-it-ness is the ability of a teacher, in this case lecturer, to read their environment and adjust accordingly. With-it-ness is an awareness of self and others (Vongalis-Macrow, 2005). An important aspect of with-it-ness is the ability to communicatewith others and sense change within an environment (Elliot, 2008; Emmer, 2001; Freytag, 2003; McDaniel \& Jackson, 2009; Ulmer, 2001). With-it-ness leads the teacher to vary the learning so that discernment and understanding can occur (Oliver \& Trigwell, 2005). With-it-ness can be tested in asynchronous ICT platforms for teaching and learning (Ferrer-Cascales, Walker, Reig-Ferrer, Fernandez-Pascual \& Albaladejo-Blazquez, 2011). Incautiously, it is possible to forget that the nature of asynchronous learning means that the learner and the educational resources are neither in the same physical space all the time nor at the same time (Muirhead, 2005).

Awareness that something was happening within the internship environment and awareness that students were working with newly established, perhaps re-established subjectivities (Peters, 1999) across a variety of spaces that I had not predicted, helped me to scan that environment for solutions. I looked for a communication means that achieved two aims:

1. Provided a means for me to communicate to students as I had previously communicated with them and that attempted to replicate my sense of fun and caring manner.

2. Engaged students in electronic forms of communication that I had seen them using on campus with their friends and family.

I hypothesized that the use of newer literacy practices in on-line environments would overcome some of the structural boundaries with which I was faced.

In the next sections I describe the significance of the research, the research puzzle in greater detail drawing on the three tension points outlined within the context of my university and programs of instruction. I provide data that show that the use of emails as informational tools tends more toward old literacy practices. I then provide data that show a difference in literacy practices once I began using a social media tool. I then outline the method that I used to analyse the data.I conclude the paper with a discussion of the different literacy practices and their roles in new pedagogical practices. The next section examines the importance of this research study.

\subsection{The Importance of the Problem}

This paper is intended to add a timely re-focussing of the types of social media and new literacy practices that university academics can add to their online teaching. Most online, blended learning programs offered in university contexts are now traditional learning tools such as emails, discussion boards, blackboard sites, wimba classrooms, blogs and so on. I find that these are not the most riveting and interesting tools to work with. This paper describes a fun social media tool that can help provide a sense of teacher with-it-ness in online classrooms. The paper is significant because it discusses tools that are not part of the institutionalized lexicon of accepted blended learning tools.

\subsection{Literature Review: A Complex Problem, Something Cracked, Dully Jarring and Dysfunctional}

Subsequently, this paper draws on the literature surrounding Web 2 technologies and exists at the intersection of at least three tension points concerning the manner in which the contemporary university now conducts business. Each of these tension points has an effect on staff and students enrolled in the programs under discussion. The tension points that I have concentrated on in this paper include discussion around the choice of complexity and 
simplicity in virtual environments, the "filling space" that is the interspace between Web 2.0 application and take-up and the conservative "tree of knowledge" dispositions of universities and their staff.

The first tension point has provided the title of this paper. I live in Queensland, a state of Australia known for its innovative education reforms (Darling-Hammond, 2010). The authors of a study of one such reform, the Queensland School Reform Longitudinal Study (Lingard et al., 2001) suggested very strongly that reform is a complex process where the simplest solution is often not the best solution. Conversely, William of Ockham a thirteenth century monk and philosopher suggested that the simplest solution can be the best solution. Ockham observed that, what "can be done with fewer assumptions is done in vain with more" (Cambourne, 2001, p.784).Although I tend toward the first definition, when I did apply a simple solution to a complex problem as outlined in this paper, it did seem to work best and did make me smile. I do not suggest that this is replicable, just that it happened.

The second tension point exists at the interspaces of Web 2.0 reform. In these spaces new norms arebeginning to emerge concerning the ways new technologies can be used to improve learning. It is clear that the hybrid form of electronic texts composed of video, graphics, images and animation, plus written texts, is very different from the print-based convention universities usually employ. Jewitt (2002) further adds that, in the transition from page to screen, students have to learn to make sense of these newer representational modes. He suggested that an interaction of students with visual texts demands that "reading' and the process of learning within school English be regarded as more than a linguistic accomplishment" (p. 171).

Earlier St Pierre and Pillow (2000) drew on Derrida (1978) to describe such interspaces as the "not-yet-thought" or the "as yet unnamable which begins to proclaim itself" (p.4). The interspace I am interested in here is the opportunity to bend Web 2 technologies to the art of good teaching. The emerging norms of virtual space for the general public are Microsoft -Apple- Facebook -games- I Tunes-Twitter and Skype saturated. The emerging norms for distance learning, defined by Rosenberg (2001) to mean the sharing of information through a computer network that enables both the end user and the sender to retrieve information in a variety of ways, has led to the use of additional tools such as WIMBA and Web CT for example. There is however space for other less well known technologies that are equally effective.

As Beavis (2000) observes, "the emergence of digital technologies and forms of online engagement that privilege interaction over information, collectively referred to under the heading of Web 2.0, raises important questions of theory and practice, and the ways in which schools and teachers might respond" (60). Working within this tension point involves teaching that is a self and others process (Vongalis-Macrow, 2005) that is more personal, more with-it, more varied (Henrique \& Kusse, 2011; Oliver \& Trigwell, 2005) and interactive. Interactive learning occurs between staff and students when the teacher establishes a sense of presence and with-it-ness with students. This relationship can be problematic in some virtual environments.

The third tension point concerns the emerging role of the university in a virtual environment. All universities have been very quick to own a Facebook page, to exhort the general public to 'follow us on twitter' and of course to embrace the endless possibilities of email and Skype technologies. I feel that there is something not quite right about this emerging virtual university environment though and I sought to investigate my sense of what is dully jarring and dysfunctioning about my relationship to that environment. I draw here on Rajchman (1985) who observed that Foucault investigated "something cracked, dully jarring or dysfunctioning in the things [he] saw, in the institutions with which [he] dealt, [and] in [his] relations with others" (46) when he undertook his research. Like Foucault, my research puzzle emerged from a sense that the emails I was expected to send to students during their offshore placements were artifacts of old literacy practices that worked well within a tree of knowledge paradigm where first branches lead to second branches of information and so on toward a linear, ordered and hierarchical state of informed awareness (Alverman, 2000). However, once students returned home, thousands of miles and time differences away from the host university, the emails I sent seemed to me to represent more dross in their learning rather than essential information. Had the content of the emails been delivered locally and face to face, it would have been revisited several times in a variety of ways (Henrique \& Kusse, 2011; Oliver \& Trigwell, 2005). This would be so that learning for discernment can occur.I suspected when I began this study that a rhizomatic (Deleuze \& Guattari, 1987; Grosz, 1994; Lather, 2000; Morgan, 2000) approach to my communication with students was preferable. Such an approach I hoped would allow the texts I sent students to exist outside of them and to lead to endless discussions and interactions between the students I was aiming to reach. I had some success with this.

Vongalis-Macrow (2005) argue that one of the reasons why teachers (and academics) feel less control over their working environment currently and thus less with-it-ness in relation to their teaching is that their autonomy to 
make free judgments about their profession and its development is decreased by the structural boundaries of globalised education. These boundaries require a new set of meta-textual awareness with communication patterns in this environment involving varied modes of communication (Jewitt, 2005; Unsworth, 2006; Kress \& van Leeuwen, 1996, 2006). These modes of communication are often unidirectional, but should be multi-directional.

\subsection{Overcoming Structural Boundaries Using New Social Media}

I had some autonomy over the work described in this paper, but when it was insufficient, I sought new ways to regain autonomy through the use of new literacy practices. New literacy practices are those that recognise that readers are increasingly exposed to communication tools and situations that are multimodal rather than linguistic. Multimodal forms of communication are those that involve multiple sign systems, multiple modalities such as picture and sound and involve recursive communication. My hypothesis was that the use of newer literacy practices in on-line environments would overcome some of the structural boundaries with which I was faced. For me, that solution was the use of the Smilebox ${ }^{\mathcal{O}}$.

\section{Method}

The study reported here is part of a broader qualitative and longitudinal research study. The qualitative methods used in this longitudinal study include the use of on-line surveys, in depth focus group interviews, semi-structured interviews and an environment scan of the relevant policies and procedures undertaken by staff and students involved in the study. The latter method is what is reported in this paper.

\subsection{Participants and Sampling Techinques}

Participants in the study are students from Canada who have enrolled in Masters of Teaching degrees in the field of primary and secondary education at a university in Queensland. Since the inception of these degrees at the research site over 3000 students have enrolled. To date over 100 students have participated in the longitudinal study. Staff members are also involved in the bigger study, but not in the section of the study reported here.

\subsection{Sampling Procedures}

There were two ways that students were approached to participate in this study. First students could self-select participation by answering an on-line questionnaire through the university's survey site. Their response to the questionnaire was considered to be consent. Particpants could also agree to involvement using the information package and consent form attached to the survey. Students could separate that consent form from the rest of the survey and email that back to the researcher. The second method was to speak with the on-campus cohort personally and provide these students with an information package and consent form. Students now participate in the study either at home in Canada, from any where in the world or here in Australia and do so via the internet or in face to face sessions.

For this small section of the study 50 students were involved nominally, meaning that their correspondence with me was monitored in light of the research hypothesis namely that the use of newer literacy practices in on-line environments would overcome some of the structural boundaries with which I was faced. For me, that solution was the use of the Smilebox ${ }^{\odot}$.

\subsection{Data from the Environmental Scan}

In order to see if newer literacy practices in on-line environments in higher education were more effective than older literacy practices such as emails, I implemented a new message sytem that used a computer package called Smilebox ${ }^{\mathcal{O}}$ I then monitored the effectiveness of each message system based in small part on the return email conversationsI had with students, but largely through the implications of each form of message for the reader. Implication was gauged through the literary device of intertextuality (Fox, 1995). The next section outlines these two message systems.

\section{Data}

In this section I outline both the emails sent to students (no. of students $=50$ ) and newer communication patterns. The newer pattern of communication is in the form of the social media tool called Smilebox ${ }^{\circ}$.

\subsection{Official Sequence of Emails}

The emails provided below, directly relate to the internship component of the teaching programs students undertake. From the environmental scan I gleaned the following official university (2010) account of the purpose of these emails:

Students are supported during the internship component of these programs. Students are in a co-teacher 
rather than student-teacher role in the internship. Students and mentors are supported through consistent and timely email contact through the internship supervisor, preparatory seminars at their host university and telephone contact with students and school mentors as necessary (for example Deputy Principals and School coordinators). Students are also supported with internship 'cluster meetings', wherein students and mentors come together to meet with university staff at a strategic point during the internship. As many of the students complete their internship in the Ontario region of Canada, a university staff member visits to hold the cluster meetings there. This is an important feature of the success of the internship semester and an important feature in building and maintaining productive relationships with Ontario schools (cluster meetings are often generously hosted by schools), School Boards and individual mentors (123-124).

These emails outline the roles and responsibilities of each participant in the process and summarize dates and timelines and assessment milestones along the way. The established pattern when sending these emails was at the beginning of each internship, after the first two weeks of the internship and just in time for the students' interim report, part way through the internship and then just preceding the final report concerning student performance.

The first email was designed to establish both a connection with staff and students in schools overseas and to outline the procedures for the first few weeks. The first email sent to both primary and secondary mentor teachers and principals contained a greeting that was meant to establish proximity and said:

Email 1: Greetings from Brisbane Australia.

First, my best wishes for 2010.I trust you have managed to enjoy the Christmas break and that you are now sufficiently refreshed to survive until the March break. I have replaced XXXX as the person looking after the internship so please feel free to contact me should you need to. As before, I would like to thank you for agreeing to place our student/s in your school. The students and academic staff really appreciate your support for our program. In all cases students have been asked to negotiate a commencement date for their internship...

The rest of the email outlined expectations of the internship and included phrases such as:

The first week is a preparation week in which the students are expected to assist with general teaching duties; after week 1 the internship begins in earnest with the student beginning teaching and other duties. In the first instance these duties could involve a few lessons a day, but then quickly build up to about a $50 \%$ load; in many ways the planning and preparation for the internee is a little non- specific as far as the exact amount of preparation and teaching is concerned; I am expecting that this will be the first of a number of emails to you; please feel free to email at any time with questions or concerns about the program or particular students; In addition we are planning our usual February visit to XXXX for the purpose of conducting cluster meetings with students and hopefully with teachers as well.At this stage our draft schedule for these meetings is as follows...

The second email was sent to remind staff about reports and to alert mentor teachers and their students to the processing of those reports. By this time in 2010, I had received many emails asking me to clarify what was in the handbook in relation to the interim report.

Email 2: Good morning everyone, I've had a few enquiries about the interim report so I thought I should comment on this aspect of the internship. The process for the interim report is outlined in the handbook.This process and the interim report itself are critical elements of the internship.Once completed the report should represent a goal statement for the student for the remainder of the internship. The interim report should be completed at a time that suits the mentor teachers. The handbook suggests that the report should be completed after 10 to 12 days of teaching, however in some instances mentor teachers may prefer to extend this period to provide more time for observation of the student.

The final email to students contained claim forms for payment, information about registration and a final thank you note to the mentor teachers and principals in the host schools. It read:

Final email: With the term drawing to a close I thought I should email you to express my appreciation for your involvement with our students. Most students are now in the final stages of their semester and are completing their major paper for their action research course.Hopefully they will soon see some light at the end of the tunnel and then begin to realise the full value of their life changing experience over the last 18 months.I do know (from their various emails) that they have a deep appreciation for your contribution to their development as a teacher. 


\subsection{Unofficial Sequence of Smileboxes ${ }^{\mathcal{O}}$}

By 2011, I was both program convenor and internship convenor and was encouraged by my Head of School to make the programs my own. Also in 2011 students left for their internships just as a series of storms and cyclones affected Queensland, Australia and students were aware of the damage that these had caused. These two events when combined with the complex problem I had of increasing my sense of teacher wit-it-ness during the internship, led me to make a number of changes in my communication with students and staff involved in the program. As well as changing the salutation and register of the emails to internees and their school supervisors and sending the emails, I also included the following Smilebox ${ }^{\circ}$ messages to students.

Smilebox ${ }^{\mathcal{O}}$ is a registered company that provides a different social media tool than the simple PowerPoint set of slides. The company advertises the software as providing more ways to share information on-line, with the facility to share the Smilebox as a greeting, a slideshow, an invitation, a collage, a scrapbook or a photo album. Sharing is through electronic Facebook, email and/or blogs. It is possible to embed photos, videos and music within each Smilebox ${ }^{\mathcal{O}}$.It is also possible to send Smileboxes ${ }^{\mathcal{O}}$ from a mobile phone using an app. for that purpose. This process unites older technologies with newer technologies and in so doing contributes to new social media Web 2.0 technologies. An advertisement on the website notes that "Smilebox makes sharing photos with your family and friends easy, unique and memorable" (http://www.smilebox.com/, 07/11/2011). The company's website also argues that the use of a Smilebox " "turns little moments into big smiles".

I hoped that this claim and the use of Smilebox ${ }^{\mathcal{O}}$ would reduce the sense of stress I felt within myself and with the students. Prior to these students leaving for their internship, I had deliberately cultivated my sense of with-it-ness (Elliot, 2008; Emmer, 2001; Freytag, 2003; McDaniel \& Jackson, 2009; Ulmer, 2001) with my students and changed their learning environment the moment I saw a negative change in them in relation to their programs. When meetings needed to be held, I provided food and a friendly set of invitations and reminders. Prior to my becoming the internship convenor, a maximum of eight students out of 100 attended these meetings. Using the personal approach meant that I had almost all students attending meetings. I also quickly replied to their concerns via email and was on campus when they needed me. On their last day on campus I held a Valedictory evening in conjunction with a cluster meeting and had full attendance. I felt confident that this time, fewer problems would arise with the internship and students would feel confident both in asking for my help and in receiving it. This was the case.

I sent three Smilebox ${ }^{\odot}$ emails. In each case the less formal Smileboxes ${ }^{\odot}$ were sent after formal email contact had been completed.

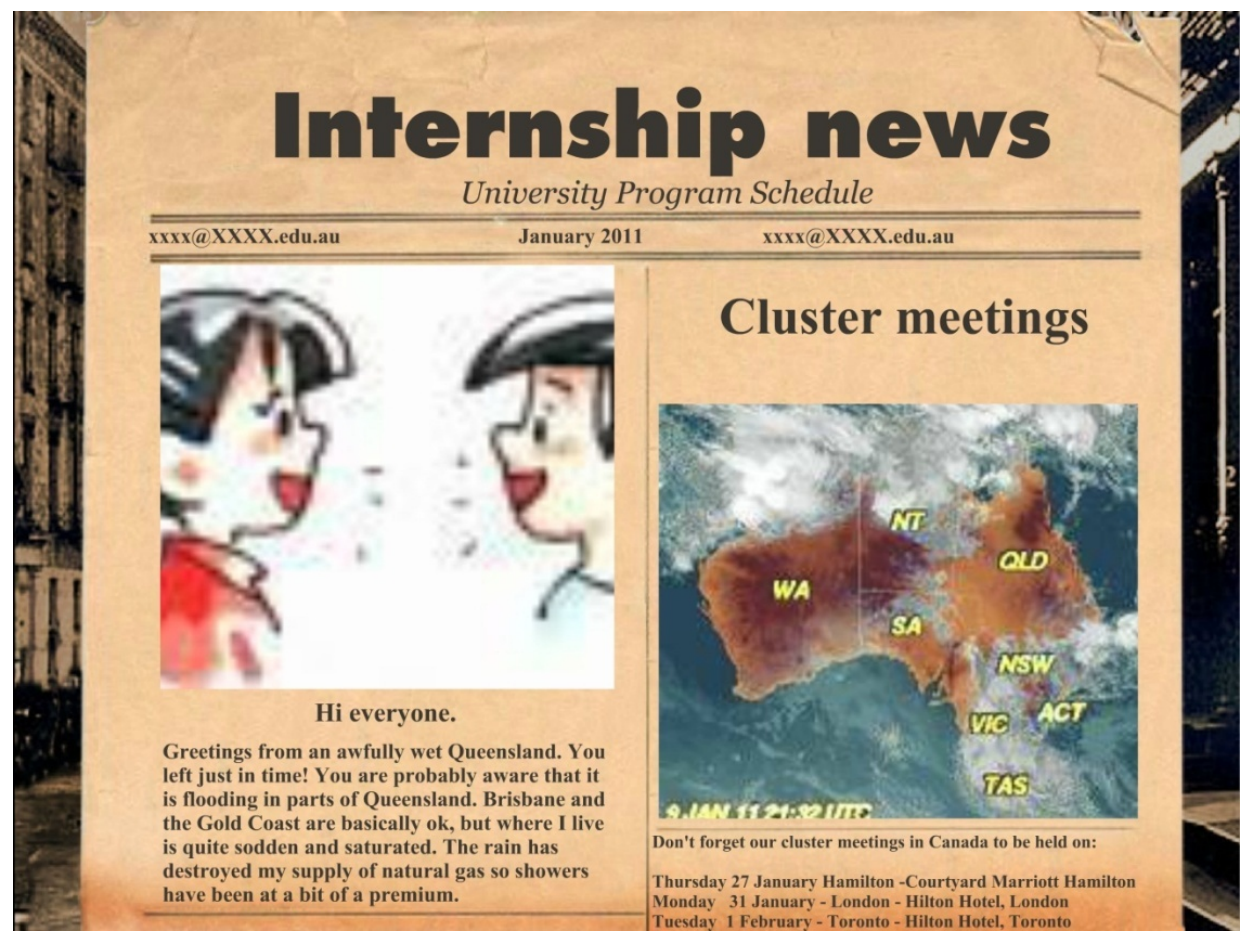

Figure 1. First Smilebox ${ }^{\odot}$ email 
This was a one page Smilebox ${ }^{\circ}$ that used two pictures and words and was sent in the first few days of the internship. This page was animated and looked like a 1950s newspaper stand, used sepia colours to age the page and used music entitled Breaking News. The salutation was less formal and said:

Greetings from an awfully wet Queensland! You left just in time! You are probably aware that it is flooding in parts of Queensland. Brisbane and the Gold Coast are basically ok, but where I live is quite sodden and saturated. The rain has destroyed my supply of natural gas so showers have been at a bit of a premium.

The title of the newsletter contains the reason for the Smilebox ${ }^{\circ}$. This newsletter was to encourage students to attend the cluster meetings that my colleague was holding in Canada.

The second Smilebox ${ }^{\mathcal{O}}$ continued the previoustheme.

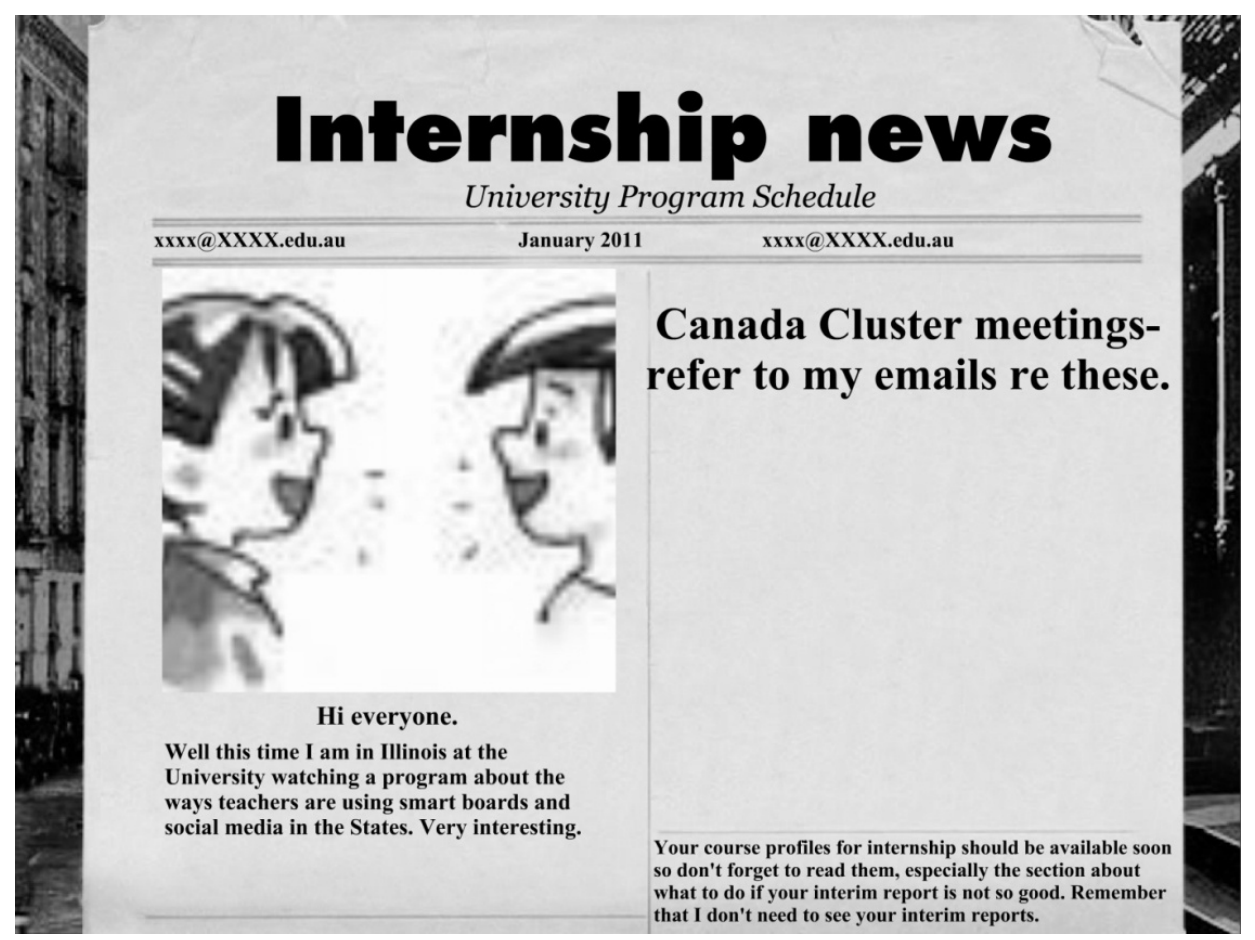

Figure 2. Second Smilebox ${ }^{\complement}$ email

The graphics in this Smilebox ${ }^{\odot}$ included the same picture as the first Smilebox $^{\odot}$ and avideo that alluded to the notion of Australia as the land down under. The message is the same. Students were exhorted to attend cluster meetings, read emails, access their course profiles and send the interim report only if there were problems with it.

In the next Smilebox ${ }^{\mathcal{\Theta}}$ Figure 3,I wassnowbound by a severe blizzard and used snow falling as the theme. Because students also complete a thesis during their internship this email was sent just as students were immersed in their research and becoming reflective practitioners. There is a photo of a key text on reflective practice provided. 


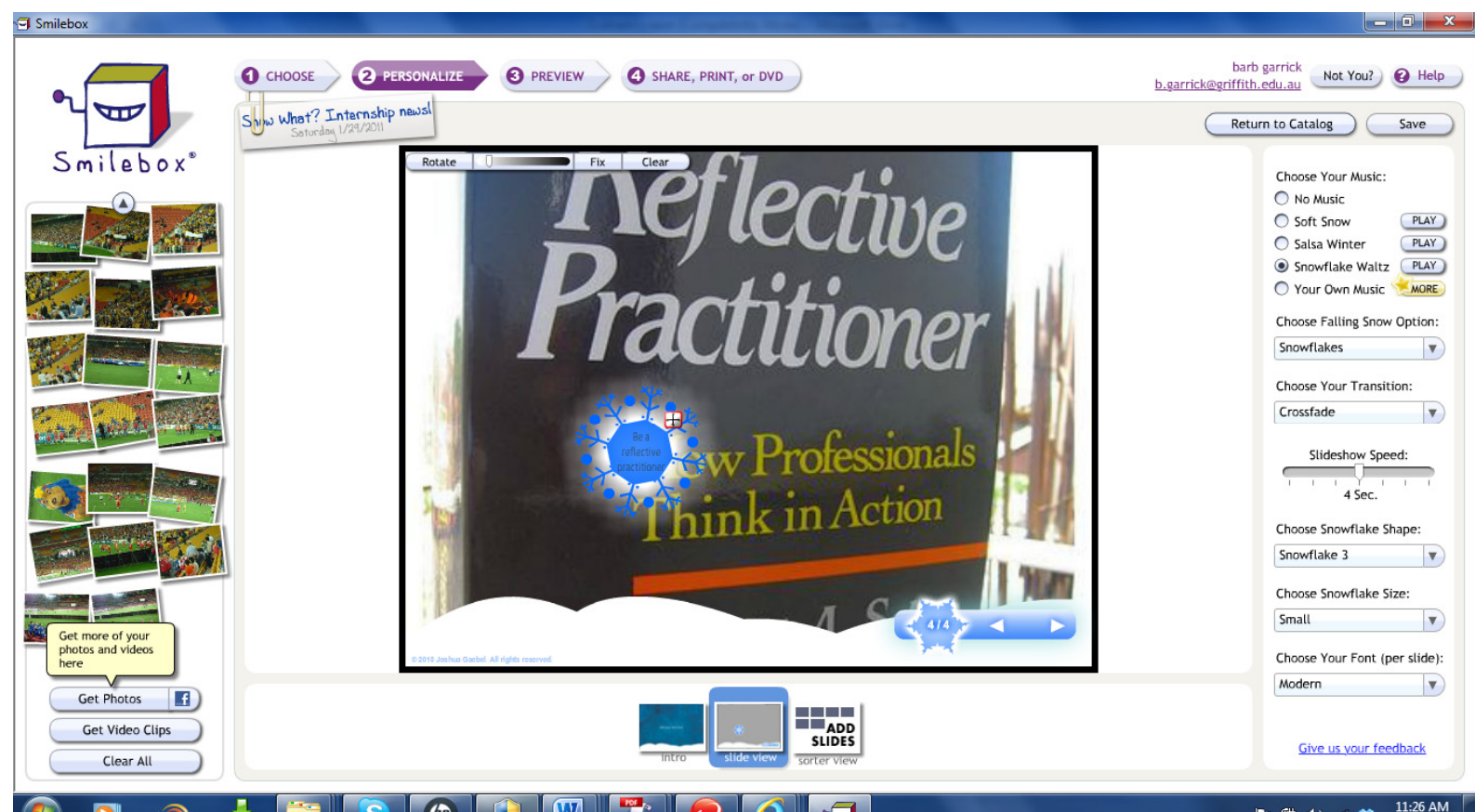

Figure 3. Third Smilebox ${ }^{\mathcal{O}}$ email

In the next few pages of this particular Smilebox ${ }^{\odot}$ further information was provided for students undertaking their internship either in Australia, in Canada or in Africa. Managing the staggered starts via email and Smilebox ${ }^{\mathcal{O}}$ was a little tricky as students were now involved in different starting dates and different programs. The primary students involved in Canada were at the interim report stage at exactly the same time as the secondary students in Canada and Australia were just beginning their internship. The starting date for the secondary students in Canada was also earlier than the starting date for the students in Australia.

In this Smilebox ${ }^{\mathcal{O}}$ there was also a slide for secondary students undertakingtheir internship at both sites. The latter pages had falling snowflakes as a background and music that accompanied the fall entitled Snowflake Waltz. The same message established in the first $\operatorname{Smilebox}^{\mathcal{O}}$ was repeated and reordered for effect. That message was:

Primary students in Canada should have their interim reports finished. I only need to see your interim report if it is bad and you are at risk. So far so good!

The next page reminded interns in Australia that they should have finished week one of their internship and this page also restated the information about the interim reports. One page exhorted secondary pre- service teachers/students to begin reading their booklets for the action research and internship components of their program and finally I thanked the academic who visited students in Canada.

There were only 3 Smilebox $^{\odot}$ messagessent. These messages were sufficient when added to preparatory work before the students left campus, to phone contact and to emails. The next section outlines what the Smilebox ${ }^{\circ}$ messages did and how each message connected to the recipients of the emails and to the things that were in their environment at the time. The analysis shows that interactive text, as part of newer literacy practices, helps bridge the gap between face-to-face discussion with students and interaction with text only. This gap is the space between Web 2.0 application and take-up. This space is where good pedagogy can occur with teachers and lecturers re-ordering text to provide the variation needed for discernment to occur (Henrique \& Kusse, 2011; Oliver \& Trigwell, 2005).

\section{Data Analysis}

In this section I begin to distinguish the differences between both forms of communication and analyse the data for the implications of each form for the reader. The discussion makes two points namely that on-line social networking capacity can improve communication as this involves new literacy practices and that the reader is affected by the multimodal text in ways that language based communication only cannot. 
First, both sets of data are examples of multimodal texts defined by Walsh (2003) to mean:

...texts that have more than one 'mode' so that meaning is communicated through a synchronization of modes. They may incorporate spoken or written language, still or moving images... and incorporate sound (p.3).

The emails are multimodal in so far as the written text can be accessed, stored and later retrieved via the internet. The emails did not contain any further hyperlinks and hypertext. The Smileboxes ${ }^{\mathcal{O}}$ howeverare multimodal in that each Smilebox ${ }^{\odot}$ contained written language, still and moving images and incorporated sound.The potential impact of this newer form of communication on learning outcomes has been understood by researchers and educators. Makin, Jones Diaz \&McLachlan. (2007) observe that literacy is changing and readers are increasingly exposed to communication tools that are multimodal rather than exclusively linguistic. They argue that this has required new thinking that defines literacy as not simply a question of print-based versus electronic or digital literacies, but a "consideration of multimodal contexts" (p.57). Based on this definition the combination of the emails and the Smilebox ${ }^{\odot}$ communications provide a broader multimodal context for the learners during their internship.

Second, all Smileboxes ${ }^{\odot}$ relied on the concept of intertextuality to connect with students. The concept of intertextuality is defined by Fox (1995) to be the process whereby one text refers endlessly to other texts (their intertexts) and to their processes of social and cultural production. Morgan (2000) further affirms that

...after Derrida (1976), textual theorists can no longer accept the notion of a self-contained text distinct from others. Instead, we recognise that texts mean in relation to other texts, which they may quote or allude to explicitly, parody or reject- or which may implicitly engage with us as part of a larger conversation whose discourses and genre mingle together in the spaces of a culture (135-136).

What follows now is an examination of the concept of intertext for the photos used, the salutation and the information provided in each Smilebox ${ }^{\circ}$.

The first Smilebox ${ }^{\complement}$ was sent just after an internal tsunami destroyed a small town near the host university. Students overseas may well have visited this town or had friends there. Had they been on campus we would have all been discussing this horrific event. Rain also engulfed the host university and students were aware that Brisbane was flooding. Each event was broadcast on CNN. It was important to assuage any concerns students may have had about our university. I sent this Smilebox ${ }^{\odot}$ to students only after the first formal email had been sent to both mentors and pre-service teachers.

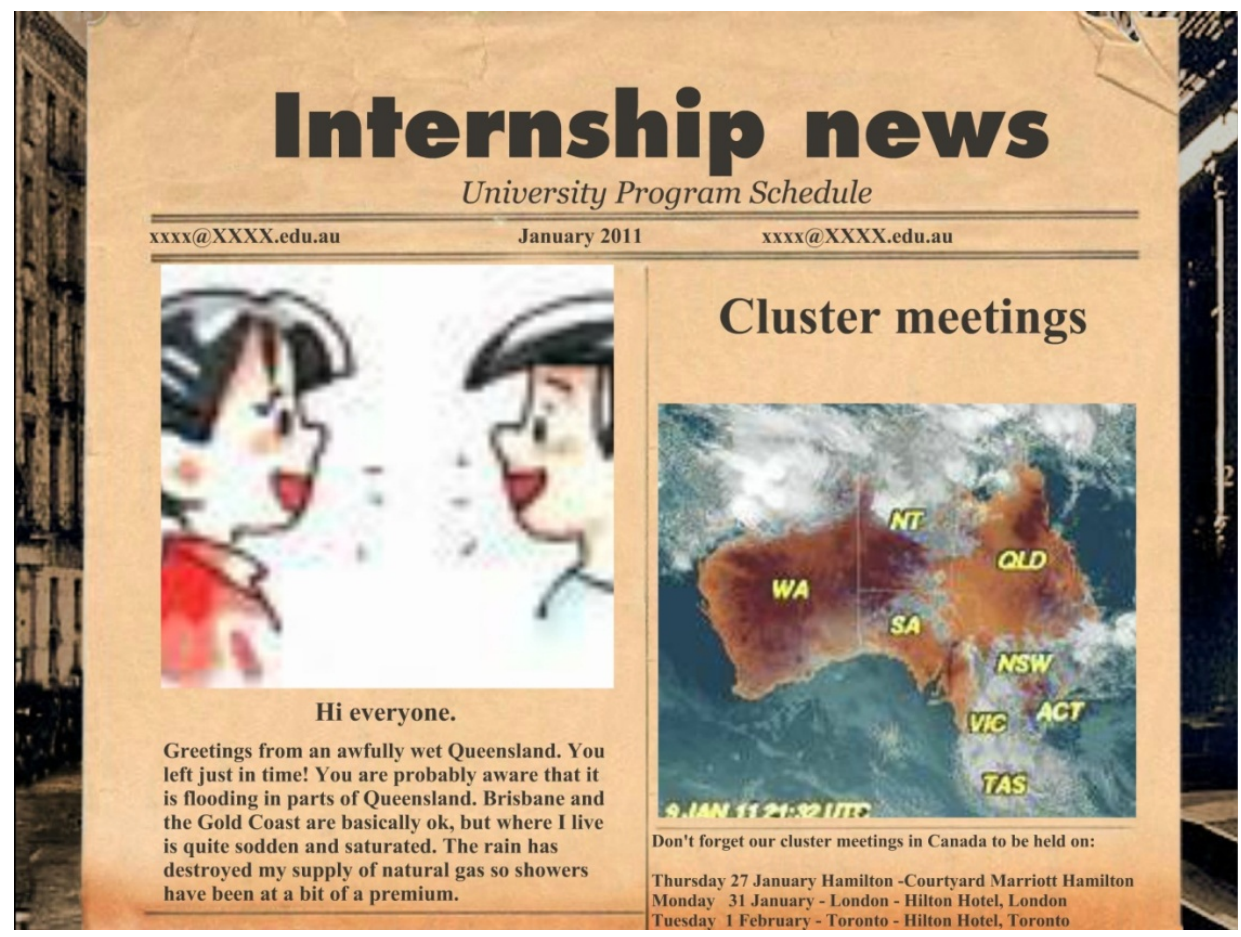

Figure 4. The photo's familiar intertext 
The photo was used because I was not visiting students in Canada this time and I wanted them to know that I was still their convenor. This drew on the intertextual relationships I had established between the students and I whilst they were still on campus. The salutation's intertext was to have someone from the university tell the students that staff and students on campus were mostly unaffected by the storms. I also inserted a picture of a weather map to show students just how wet it then was in Queensland. Smilebox ${ }^{\mathcal{C}}$ allows you to add video and I thought of adding some video of the destruction occurring in the state of Queensland because of the floods, but decided that this was not necessary and in fact inappropriate.

The reference to the cluster meetings drew on two intertexts. First, a colleague of mine was visiting the students this time and I did not want her to be disappointed with the number of students attending. The link to me was that I remembered being disappointed when students didn't attend meetings in 2010. The second intertext was my awareness that students were stressed in the first few days of their internship. To offset this stress I provided only the key dates and the venues. I did this because I am aware that students need considerate texts when stressed or overwhelmed. Foreman (2011) defines a considerate text as a text where the teacher or producer of the text reduces the text's complexity and difficulty without compromising the message of the text. In the first Smilebox ${ }^{\circledR}$ I simply wanted students to know where and when cluster meetings were being held for them.

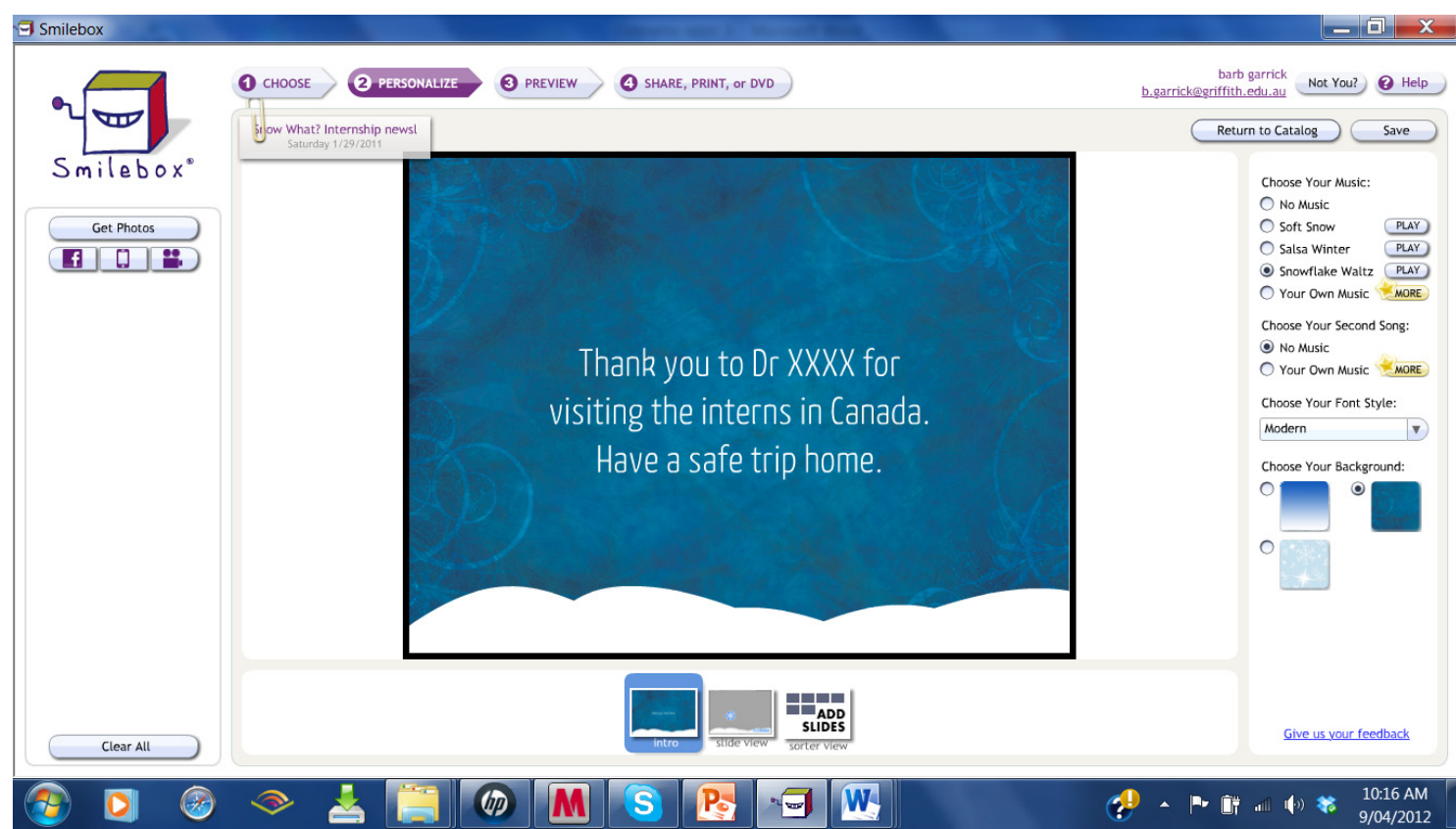

Figure 5. The use of geography and sound as an intertext

In this Smilebox ${ }^{\odot}$ the pictures used were to remind them of both my role and of their recent Australian association. I used a line from an iconic Australian song by Men At Work (Hay \& Strykert,1981) entitled Land down under in order to link the old with the new.

The latter note that repeated the advice about their interim reports was to prevent the countless emails asking how to return the interim report. Although this information was in the emails and the handbook, students and staff had not understood this in the previous year. I also wanted students to have a sense of what can be done through distant communication. Although I was off campus myself and in the United States, I wanted students to know that I was still in touch. 


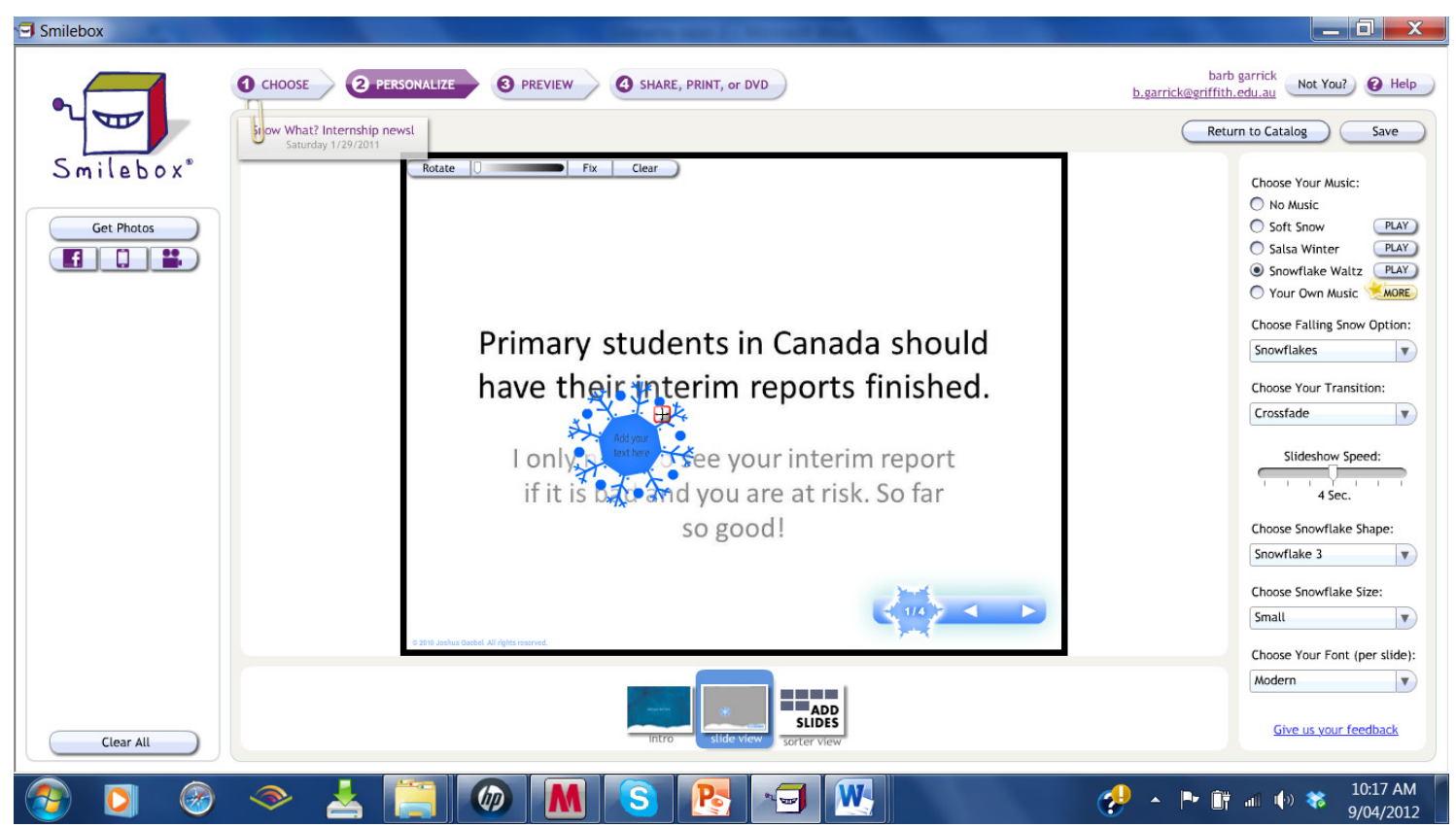

Figure 6. The use of snow as an intertext

In this Smilebox ${ }^{\circ}$ snow was used for its intertextual relationships between the students and I.The use of snow played on the words of Herodotus:

It is said that as many days as there are in the whole journey, so many are the men and horses that stand along the road, each horse and man at the interval of a day's journey; and these are stayed neither by snow nor rain nor heat nor darkness from accomplishing their appointed course with all speed (trans. Glover, 1924)

I wanted students to know that I was aware of their needs at that point in time and would do my best to assist them and that I would be deterred "neither by snow nor rain nor heat". To my mind this allusion connected the heat and darkness of once sunny Queensland Australia with the snow and rain of Canada. I was also aware that this particular phrase was often attributed to the United States Postal Service. This was an intentional allusion that was closer to home for these students, just across the border in fact where I was then located.

The second page of this particular Smilebox ${ }^{\mathcal{O}}$ was my way of managing the staggered starts each group undertook in the internship process. I also hoped that it would alert students to my role in managing many students across different spaces. I hoped that this would help them in two ways, namely to manage themselves better before asking for help from me and to see the size of the program and the number of students I was responsible for. This was intended to alert all students to their own geographic location within a more globalized set of locations.

\section{Discussion: What the Texts Did: Email: $\operatorname{Smilebox}^{\circledR}$ What Smilebox $^{\circledR}$ ?}

The emails and the Smileboxes ${ }^{\odot}$ are now examined for their implication.The major finding is that when I used the Smileboxes" ${ }^{\mathcal{O}}$ I felt less "cracked", "less jarred" and less "dysfunctional" about what I saw, with the institutions with which I dealt and in my relations with others. I felt as though I had regained my sense of with-it-ness with students and I felt as though I had tried to vary the messages students and teachers were sent so that information was less obscure for them. This digital software enabled me to change the register (Lather \& Smithies, 1997) and tone of my contact with students once the more formal emails were sent. Morgan (2000) observes that multimodal text, such as that used in Smilebox ${ }^{\mathcal{O}}$ turns a different face to the reader through the forward and backward motion of the text and its intertexts, intratexts and hypertexts. Each Smilebox ${ }^{\odot}$ drew on an accretive set of memories, empathies and associations to be made individually. This was a concept that signified 'and/and/and...' when compared with the "...single, complete truth" (Morgan, 2000, p.134) provided in the coherent and crafted emails. Morgan further asserts that

In a word, the difference between print and hypertext is between place and space. It is between on the one 
hand, the apparent stability in print, of contexts and hence meanings created by the fixed sequence of paths (words, sentences, paragraphs, sections, chapters, parts, front and end matter and sequences of chronology...) and, on the other, the indeterminacy of a hypertext with its nodes like so many shards of coloured glass that fall into ever new patterns as the viewer turns the device" (p. 131).

The Smilebox ${ }^{\mathcal{O}}$ software helped me to create associative reading. As Morgan (1999) observes "a text that displays the patterns of its weaving promotes the tendency to play over and through its web to produce other readings" (p.209).

A search of my email inbox for the period of time in question also reveals that I received fewer emails of inquiry $(\mathrm{n}=2)$ from students and mentor teachers than in previous years once the Smileboxes ${ }^{\mathcal{O}}$ were sent. Indeed, for the very first time I received the following emails from a student asking why they had not received their Smilebox ${ }^{\circ}$ and two emails from staff. One staff email was from the Internationalisation convenor and the other was from the Head of School.

To: [author's name]

Hi [author's name],

I seem to have missed an email from you? Something re smilebox??The girls told me to contact you. ps, my email i check every day is s...n@gmail.com

Thanks

Suzanne

I also received the following email from my colleague in Canada:

To: [author's name]

Hi [author's name],

I love your Newspapers!!!! I have today finished all the fairs so now ready to turn my brain to the cluster meetings. Just now I have started to be a little concerned about them - and maybe the students' reactions. Fingers crossed. Will email after tomorrow's meeting.

Regards

Kay

My Head of School also noted that she loved this form of communication with students and found it "very catchy indeed" (personal communication, 02/02/2011).

Rather than judge whether this approval from colleagues and students was because of a change in text form and rather than worrying over determining how and why the text of the Smileboxes ${ }^{\mathcal{O}}$ worked for me, I now draw on Deleuze and Guattari's (1987) concept of rhizomatics to explain what might have happened. The concept of rhizomatics refers to a means to "move between things in ways that nullify beginnings and endings' (Alverman, 2000, p.116). In a rhizomatic analysis of text, meaning is gained between texts via their intertexts. This method of analysis works with the data as it was the middle part of the communication process that I had some control over. In this middle it is clear that no text is neutral. All texts are situated within contexts that draw meaning from the texts' intertexts. As Grosz (1994) observes,

It is...no longer appropriate to ask what a text means, what it says, what is the structure of its interiority, how to interpret or decipher it. Instead one must ask what it does, how it connects with other things (including its reader, its author,( its literary and nonliterary context) (p.199).

Deleuze and Guattari (1987) are interested in the ways texts function outside themselves, believing that "texts, like rhizomes connect with other things (e.g. readers, other texts, contexts)" (Alverman, 2000, p.117). Texts help both reader and writer connect with other things in order to create meaning.

In the first year as internship convenor, I did not personally connect with the emails I was initially provided to send to students. As a new learner in my role, I was faced with emails that I thought had too many words. This is not to argue that the words were unnecessary or the process incorrect. However, I had difficulty honing in on the important concepts in each email and I understand why students and mentor teachers miles away also had difficulty. These emails implied a fixed sequence of paths to me from words to sentences to paragraphs and on into a hierarchical ordering of content, much like the constructivist tree of knowledge metaphor so often used with education (Davis \&Sumara, 2002; Mullholland, 2005; Saban\&Kocbeker, 2007) and referred to by Deleuze and Guattari (1987) as the "infamous tree" (p. xiii) of western binary and linear systems of thought. At that stage 
I was unfamiliar with this content. Because the emails were not of my own creation and because these were written by someone higher in the academic bureaucracy than I, I knew that I had to send the emails as they were written. I sensed fixity not of my own making. The emails to me were a product to be unquestioningly digested. I am well aware that this fixity is important in the legal and organizational discourse of a contemporary university. When I did have some ownership of the emails in 2011, it is important to note that only the salutation changed in the emails. The content and the timing remained the same.

The text of these emails though had intertexts. Individual reading of a series of emails meant that students and mentor teachers both in Canada and here would not interpret the emails in exactly the same way and at exactly the same time as intended by the author of the emails. This meant that more emails in reply to my emails were inevitable.

\section{Implications for Practice}

I make two major points in relation to the content of this paper and its implication. The first point is that there is a need to redefine literacy in the electronic age for university educators. A redefinition of literacy within a university Web 2.0 environment entails the development of a metalanguage so that students and lecturers have access to the skills required to better communicate in that environment. Learning as social participation is important. Such participation must have an emphasis on "the negotiation of meaning rather than on the mechanics of information transmission and acquisition" (Wenger, 1998,p.265). Wenger further asserts that it is through the routine negotiation of meanings, rather than the information acquisition and transmission, that members in the community learn, and thus continue their participation and engagement. The multimodal environments available to students and their lecturers are complicated and multifaceted (Levy \&Kimber, 2009). This paper has attempted to show though that the use of multimodal texts in virtual environments is far more effective than the use of emails as an electronic form of a handout or letter. The paper has also shown that the not-yet-thought of interspace between the Web 2.0 environment and teaching can be filled with better pedagogy or at the least the attempt at better pedagogy.

As noted, I drew on multimodal text forms that I had seen students use on campus. Students were able to use the Smileboxes $^{\mathcal{O}}$ and subsequently the email traffic that asked for confirmation of the content of each Smilebox ${ }^{\mathcal{O}}$ diminished dramatically $(n=2)$. The use of the Smileboxes ${ }^{\mathcal{O}}$ seemed to seamlessly link the traditional university environment with the emerging virtual university environment. In this virtual learning environment it is the lecturer and not the student who needs to use newer literacy practices to inform their teaching. When I applied my sense of with-it-ness, my sense of variation and consolidation to the content of the Smileboxes ${ }^{\circ}$, I felt more in touch with the students, the virtual environment and the task. University academics need to manage the virtual environment using the pedagogy of the classroom. I have argued in this paper that lecturers/teachers have a unique set of pedagogic skills that include their sense of self and others (Vongalis-Macrow, 2005), their understanding that content needs to be provided in a variety of ways for learning to occur (Oliver \& Trigwell, 2005) and their duty to provide considerate texts that teach as the student reads (Foreman, 2011). Of most importance is the sense of with-it-ness that a teacher brings to the classroom (Elliot, 2008; Emmer, 2001; Freytag, 2003; McDaniel \& Jackson, 2009; Ulmer, 2001).

The second point is that the discussion in this paper can be enhanced by further examination of what the Smileboxes ${ }^{\mathcal{O}}$ did to the reader. This investigation can be undertaken using an on-line survey such as that suggested by Ferrer-Cascales et al. (2011) who argue that most post-secondary institutions now use asynchronous teaching and learning environments described variously as e-learning, distance learning, open learning, on-line learning and /or blended learning. The burgeoning variety of text forms when combined with the burgeoning variety of spatial and pedagogic environments require new literacy pedagogy. The next task for the research project reported here is to survey students further to see how the different forms of burgeoning text are/were received. This survey will use Walker and Fraser's (2005) Distance Education Learning Environment Survey (DELES). This survey is a 34 item questionnaire where participants rank their experience of distance and on-line learning on a Likert scale of always, often, sometimes, seldom, never. The 34 items measure six relevant psychosocial scales of instructor support, interaction and collaboration among students, personal relevance of the class work, authentic learning, active learning and student autonomy. As suggested by Ferrer-Cascales et al. I will add further questions concerning participants' additional study situation and affect especially in relation to the virtual support provided once students return to their home country. This survey may add further data that explores the assumption in this paper that the use of multimodal text forms with students within distance learning environments is preferable. 


\section{Conclusion}

To cut down on the number of reply emails from students and mentor teachers, to encourage students to read the emails, to maintain my sense of with-it-ness with students and to improve on previously poor communication practices, I turned to the Smilebox ${ }^{\mathcal{O}}$ software and hoped that it would mimic my teacher persona in some way. I wanted to learn how to better use the virtual environment of the contemporary university and I wanted that learning to be simple rather than complex. At the same time I wanted to open up a virtual space where my students and I could perform as we had done before the students left Australia. I also wanted to separate print from this performance and use it only as an informative tool to be accessed if the Smileboxes ${ }^{\mathbb{O}}$ had not worked. I hope that I have opened a space to students that played with the idea of space and place through the use of intertext and hypertext. Intertexts performed the complex work adopted through the simple solution of the Smileboxes ${ }^{\mathcal{O}}$.I hope that newer literacy practices of multimodal forms have produced a becoming space in the interspaces of Web 2.0 technology that is more collaborative. It is in the interspace of technology that there is room to maneuver between the tension- points that exist in the contemporary university market.

\section{References}

Alverman, D. E. (2000). Researching libraries, literacies, and lives: A Rhizonanalysis. In E. A. St Pierre \& W. S. Pillow (Eds.), Working the ruins: Feminist poststructural theory and methods in education (pp.114-130). New York: Routledge.

Beavis, C. (2000). Computer games as class readers: Developing literacy skills for thetwenty-first century. The English and Media Magazine, Spring 2000(41), 31-35.

Beavis, C. (2001). Digital cultures, digital literacies. In C. Durrant \& C. Beavis (Eds.), (PICT)ures of English: Teachers, learners and technology. Kent Town, SA: Wakefield Press/AATE.

Cambourne, B. (2001). Conditions for Literacy Learning: Why Do Some Students Fail to Learn to Read?. Ockham's Razor and the Conditions of Learning. The Reading Teacher, 54(8), 784-786. Retrieved from http://www.jstor.org/discover/10.2307/20204993?uid=3737536\&uid=2\&uid=4\&sid=21101212403413

Darling-Hammond, L. (2010). The flat world and education: How America's commitment to equity will determine our future. USA: Teachers' College Press.

Davies, J., \& Merchant, G. (2009). Web 2.0 for schools: Learning and social participation. New York: Peter Lang.

Davis, B., \& Sumara, D. (2002). Constructivist discourses and the field of education: Problems and possibilities. Educational Theory, 52(4), 409-428. http://dx.doi.org/10.1111/j.1741-5446.2002.00409.x

Deleuze, G., \& Guattari, F. (1987). A Thousand Plateaus (B. Massumi, Trans.). Minneapolis: University of Minnesota Press.

Derrida, J. (1976). Of Grammatology (G. C. Spivak, Trans). Baltimore: John Hopkins University press.

Derrida, J. (1978). Writing and difference. Chicago: University of Chicago Press.

Durant, C., \& Beavis, C. (2001). (PICT)ures of English: Teachers, learners and technology. Kent Town, SA: Wakefield Press/AATE.

Elliot, J. G., \& Stemler, S. E. (2008). Personnel preparation: Teacher authority, tacit knowledge and the training of teachers. Advances in learning and behavioral disabilities, 21, 75-88. http://dx.doi.org/10.1016/S0735-004X(08)00003-7

Emmer, E. T. (2001). Classroom management: A critical part of educational psychology, with implications for $\begin{array}{llll}\text { teacher education. } & \text { Educational }\end{array}$ http://dx.doi.org/10.1207/S15326985EP3602_5

Ferrer-Cascales, R., Walker, S. L., Reig-Ferrer, A., Fernandez-Pascual, M. D., \& Albaladejo-Blazquez, N. (2011). Evaluation of hybrid and distance education learning environments in Spain. Australian Journal of Educational Technology, 27(7), 1100-1110. Retrieved from http://www.ascilite.org.au/ajet/ajet27/ferrer-cascales.pdf

Flourish. (2012, November 21). Down under map. Retrieved from http://flourish.org/upsidedownmap

Foreman, P. (2011). Inclusion in Action (3rd ed.). South Melbourne: Cengage.

Fox, N. J. (1995). Intertextuality and the writing of social research. Electronic Journal of Sociology, 1001(2), 1-16. http://dx.doi.org/10.1080/0142569950160206 
Freytag, C. E. (2003). Professional Licensure: A desecration of teacher preparation. The Educational Forum. 67(1), 56-62. http://dx.doi.org/10.1080/00131720208984534

Glover, T. R. (1924). Herodotus. Berkeley: University of California Press.

Grosz, E. A. (1994). Volatile bodies: Toward a corporeal feminism. Bloomington: Indiana University Press.

Hay, C., \& Strykert, R. (1981). Down Under. Business as Usual. Australia: CBS.

Henriques, J. B., \& Kusse, L. I. (2011). Students Who Aren't Prepared for College Find Less Value in Books and Lecture than Students Who Are Prepared. International Journal for the Scholarship of Teaching and Learning, 5(2), 1-10. Retrieved from http://www.georgiasouthern.edu/ijsotl

Jewitt, C. (2005). Multimodality, "reading" and "writing" for the twenty first century. Discourse: Studies in the cultural politics of education, 26(3), 315-331. http://dx.doi.org/10.1080/01596300500200011

Kress, G., \& van Leeuwen, T. (1996). Reading Images: Thegrammar of visual design. New York: Routledge.

Kress, G., \& van Leeuwen, T. (2006). Reading Images: The grammar of visual design (2nd ed.). Geelong: Deakin University Press.

Lather, P., \& Smithies, C. (1997).Troubling the angels: Women living with HIV. Boulder: Westview Press.

Levy, M., \& Kimber, K. (2009). Developingan approach for comparing students' multimodal text creations: A case study. Australasian Journal of Educational Technology, 25(4), 489-508. Retrieved from http://ascilite.org.au/ajet/ajet25/levy.html

Lingard, R. L., Ladwig, J., Mills, M. D., Hayes, D., \& Luke, A. (2001). The Queensland School Reform Longitudinal Study: A Strategy for Shared Curriculum Leadership. Teachers' Manual. Brisbane: Education Queensland.

Makin, L., Jones Diaz, C., \& McLachlan, C. J. (Eds.). (2007). Literacies in childhood: Changing views, challenging practice. Sydney: Elsevier.

McDaniel, L. A. W., \& Jackson, A. (2009). Can "withitness skills" improve instruction and safety for those who coach or train?. International Education Studies, 2(3), 172-175.

Morgan, W. (2000). Electronic tools for dismantling the master's house: Poststructuralist feminist research and hypertext poetics. In E. A. St Pierre \& W. S. Pillow (Eds.), Working the ruins: Feminist poststructural theory and methods in education. New York: Routledge.

Muirhead, J. (2005). Growing the tree of teacher knowledge: Ten years of learning to teach elementary science. Journal of Research in Science.

Oliver, M., \& Trigwell, K. (2005). Can 'blended learning' be redeemed? E-Learning, 2, 17-26. http://dx.doi.org/10.2304/elea.2005.2.1.2

Peters, M. (1999). Globalisation and the crisis in the concept of the modern university. Australian Universities Review. Palmerston North, New Zealand: Dunmore Press.

Rajchman, J. (1985). Michel Foucault: The freedom of philosophy. New York: Columbia University Press.

Rosenberg, M. J. (2001). E-learning: Strategies for delivering knowledge in the digital age. New York: McGraw-Hill.

Saban, A., \& Kocbeker, B. N. (2007). Prospective teachers' conceptions of teaching and learning revealed through metaphoranalysis. Learning and Instruction, 17(1), 29-41. http://dx.doi.org/10.1016/j.learninstruc.2007.01.003

Smilebox. (2011). Retrieved July 11, 2011, from http://www.smilebox.com

St Pierre, E. A., \& Pillow, W. S. (Eds.). (2000). Working the ruins: Feminist poststructural theory and methods in education. New York: Routledge.

Unsworth, L. (2006). Towards a metalanguage for multiliteracies education: Describing the meaningmaking resources of language-image interaction. English teaching: Practice and critique, 5(1), 55-76.

Vongalis-Macrow, A. (2005). I, Teacher: Agency in globalised education. Paper presented at the Australian Association for Research in Education Annual Conference, Parramatta, NSW.

Walker, S. L., \& Fraser, B. J. (2005). Development and validation of an instrument for assessingdistance education learning environments in higher education: The Distance EducationLearning Environments Survey (DELES). 
Learning Environments Research, 8(3), 289-308. http://dx.doi.org/10.1007/s10984-005-1568-3

Walsh, M. (2003). Reading' pictures: What do they reveal? Young children's reading of visual texts. Reading, 37, 123-130. http://dx.doi.org/10.1046/j.0034-0472.2003.03703006.x

Wenger, E. (1998). Communities of practice: Learning, meaning and identity. Cambridge: Cambridge University Press. 